\title{
Prioritizing people and rapid learning in times of crisis: A virtual learning initiative to support health workers during the COVID-19 pandemic
}

\author{
Beth Engelbrecht ${ }^{1,2,3}$ | Lucy Gilson ${ }^{2,4}$ (1) | Pierre Barker ${ }^{3,5}$ | \\ Krish Vallabhjee $^{1}$ | Gareth Kantor ${ }^{3}$ | Mike Budden ${ }^{6}$ | \\ Anita Parbhoo ${ }^{7,8}$ | Uta Lehmann ${ }^{9}$
}

${ }^{1}$ Western Cape Government: Health, Cape Town, South Africa

${ }^{2}$ Health Policy and Systems Division, School of Public Health and Family Medicine,

University of Cape Town, Cape Town, South Africa

${ }^{3}$ Institute for Healthcare Improvement, Boston, USA

${ }^{4}$ Department of Global Health and Development, London School of Hygiene and Tropical Medicine, London, UK

${ }^{5}$ Department of Maternal and Child Health, Gillings School of Global Public Health, University of North Carolina at Chapel Hill, Chapel Hill, North Carolina, USA

${ }^{6}$ Chapman and Co Consultants, St. Louis, Missouri, US

${ }^{7}$ Red Cross War Memorial Children's Hospital, Cape Town, South Africa

${ }^{8}$ Department of Paediatrics and Child Health, Faculty of Health Sciences, University of Cape Town, Cape Town, South Africa

${ }^{9}$ School of Public Health, University of the Western Cape, Cape Town, South Africa

\section{Correspondence}

Uta Lehmann, School of Public Health University of the Western Cape, PBag X17, Bellville 7535, South Africa.

Email: ulehmann@uwc.ac.za

\begin{abstract}
The Western Cape province was the early epicentre of the coronavirus disease 2019 pandemic in South Africa and on the African continent. In this short article we report on an initiative set up within the provincial Department of Health early in the pandemic to facilitate collective learning and support for health workers and managers across the health system, emphasising the importance of leadership, systems resilience, nonhierarchical learning and connectedness. These strategies included regular and systematic engagement with organised labour, different ways of gauging and responding to staff morale, and daily 'huddles' for raid learning and responsive action. We propose three transformational actions that could deliver health systems that protect staff during good times and in times of system shocks. (a) Continuously invest in building the foundations of system resilience in good times, to draw on in an acute crisis situation. (b) Provide consistent leadership for an explicit commitment to supporting health workers through decisive action across the system. (c) Optimise available resources and partners, act on improvement ideas and obstacles. Build trusting relationships amongst and across actors.
\end{abstract}




\section{KEYWORDS}

collaboration, COVID-19, health workforce support, leadership, learning, resilience, sense-making

\section{1 | INTRODUCTION}

The Western Cape (WC) province was the early epicentre of the coronavirus disease 2019 (COVID-19) pandemic in South Africa and on the African continent. Rapid increases in infections and community transmission from about mid-April 2020 required a rapid and extensive reorganisation of health services throughout the system: This included: setting up COVID wards in hospitals and building and equipping several field hospitals within months, reorganising primary care facilities to separate potential COVID patients from others, finding and purchasing vast amounts of personal protective equipment and oxygen, ensuring levels of cleanliness in facilities never seen before, training health professionals and auxiliary staff in new (and constantly changing) protocols; setting up contact tracing; and decanting services from facilities into communities. System leaders and managers were supporting a health work force who were themselves increasingly infected with and dying from COVID (8617 infections-27\% of the health workforce-and 120 deaths by February 2021), increasingly fearful about infection risk to themselves and loved ones, and progressively exhausted from prolonged and demanding work shifts.

In this short article we report on an initiative set up within the provincial Department of Health early in the pandemic: a collaborative rapid learning approach (called the \#StaffCare Colab Initiative), which shone the spotlight on the wellbeing of healthcare workers (HCWs). The initiative grew out of a series of virtual meeting events (Colabs) that provided a space for reflection-a pause moment for health care leaders and managers to support each other. Colabs provided a structured opportunity to share challenges and ideas for better support of staff, learn about simple methods to strengthen the system and better support staff, and encouraged the practice of learning itself, both within and across facilities/settings.

\section{PROCESS AND STRUCTURE}

It is important to note that the WC's health system response to COVID-19, which was lauded as decisive and exemplary by the chairperson of the South African COVID-19 ministerial advisory committee, ${ }^{1}$ built on years of investment in health systems strengthening and organisational change in the province, encouraging innovation, supportive leadership, a learning culture and collaborative governance. ${ }^{2-5}$ A 20 years whole system analysis of the province highlighted stable management and dispersed leadership as critical success factors. ${ }^{6}$ Key systems responses during COVID-19 focused on governance for health through containment strategies in other sectors and communities, as well as governance of health, ensuring a responsive health care platform.

The Department's Colab initiative was led by a Facilitation Team (FT) made up of two senior leaders in the Department and four volunteering experts from the Institute for Healthcare Improvement (IHI), the University of Cape Town School of Public Health, and a leadership coach. The FT established and guided virtual weekly meetings of the Focus Group (FG), a group of innovators comprised of mid- and senior-level managers, and senior clinicians, who met weekly for an hour. The FG was the primary sounding board for surfacing challenges in protecting and supporting staff during the pandemic, and was a venue for proposing solutions. The FG participants were given simple analytic frameworks and quality improvement (QI) implementation strategies to test ideas that could result in better staff care. Mentoring support was made available to innovators between engagements to apply simple QI. Starting in May 2020, a monthly, virtual (Zoom) system-wide 2-h Colab event, attended through open invitation by 120-220 HCWs and managers from all levels of the health care system in the province, as well as collaborating academics, provided a platform where innovations, insights and lessons were shared, and the scaling of promising 
solutions to other settings was discussed and encouraged. These 120-min Colab sessions always included: A moment of silence for those who lost their lives and loved ones, an assessment of the general mood and morale, data presentations of infection trends in staff, and the use of virtual 'chat rooms' to share stories and ideas among staff in small groups. A central part of the meetings were presentations and discussions of ideas implemented by and selected from the innovations implemented by FG members. It furthermore frequently included brief tutorials on a relevant topic such as interpreting data, steps to create change, and how to apply a simplified rapid improvement cycle (measure-understand-act) to support staff.

The design of the Colab initiative was importantly influenced by the following:

1. The recognised importance of creating a flexible, relational, safe space for engagement, beyond the usual bureaucratic spaces, structures and experience.

2. The principles of the $I H I$ Breakthrough Series ${ }^{7}$ where learnings gained from rapid action cycles are shared across the system to build communities of improvement practice.

3. The April 2020 paper by Shanafelt et al. ${ }^{8}$ on the needs and desires of staff to alleviate sources of anxiety in the COVID pandemic: Hear me, Protect me, Prepare me, Support me, Care for me.

Ideas that were tested with demonstrable impact focused on leadership interventions in various contexts. At Red Cross War Memorial Children's Hospital, a large tertiary paediatric hospital, the focus was on building relationships with organised labour as well as improving the reach of communication. ${ }^{9}$ At New Somerset Hospital, a secondary hospital, an anaesthetist used a simple measurement-asking staff to deposit marbles into a 'good day' or 'bad day' bottle-to gauge work-day experiences, staff morale and impact of interventions. At the provincial laundry a manager used a timeline that showed the impact of interventions to successfully address fear and anxiety of workers. The FG codesigned a survey tool, based on the results of the study of health worker needs by Shanafelt, ${ }^{8}$ which was used to measure emotional wellbeing of health workers in three hospitals. Several participants progressed to test more than one idea in this period. Nearly all members adopted the use of team huddles ${ }^{10}$ as a means of connecting in teams and to streamline communication. Huddles take place across the health system and its application has been modified for the specific setting.

An intensive round of FG reflections surfaced the challenges and successes of leadership efforts to protect and support health workers. A sensemaking framework (Figure 1) was codesigned, with FG members incorporating a range of these learnings. This organising framework was used to assemble ideas for achieving the goal of protecting and supporting health workers.

\section{3 | RESULTS}

What did we learn? The collective learning was multifacetted and multidimensional, encompassing numerous lessons about organisational learning, distributed leadership, as well as the needs and resilience of HCWs in acute crisis situations. In this brief report, we are highlighting elements of our learning that we believe are pertinent for rapid responses by leaders and managers to future crises in healthcare settings on the African continent and beyond.

\section{1 | Pre-existing system resilience:}

Most importantly, system resilience created prior to the acute crisis was the foundation for the transformational responses to shocks and stresses ${ }^{3}$ in the pandemic. The 20-years investment in organisational change and collaborative governance, as well as consistent messaging and role-modelling from senior management, created an environment of trust and comfort with change, which allowed for: 


\section{Sense-making framework for action to protect the health workforce}

Aim

\begin{tabular}{|c|}
\hline Healthy and \\
Functional \\
Work Force \\
\\
Zero HCW infections \\
@work \\
Staff Absences $<5 \%$ \\
Strong Staff Emotional \\
Health \\
\hline
\end{tabular}

Key Action Streams

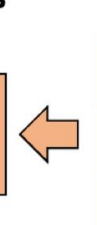

Effective Leadership and Management
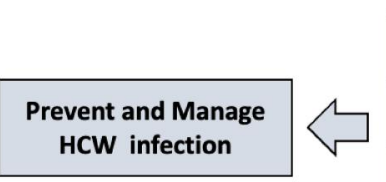

Preserve Mental and Physical Health of HCWs
Staff-staff infection prevented

Patient-staff infection prevented

Management of exposed health workers

Staff are knowledgeable and prepared

Staff anxiety prevented and managed

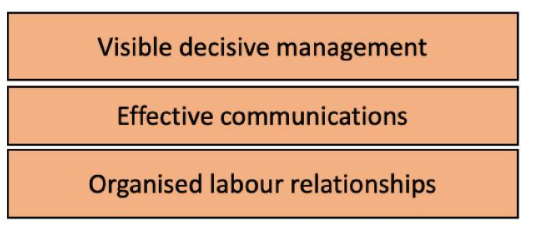

Care of basic needs \& work environment

FIGURE 1 Sense-making framework for action to protect the health workforce. Source: authors' own figure

- The 'usual' hierarchy to be 'dismantled'.

- Control/micro-management and bureaucracy to be reduced.

- Staff to step out of their usual roles to respond to system needs.

- Experimentation and rallying actors across the system to be part of the solutions to which senior leadership did not have the answers.

- Communication and transparency in sharing of information, challenges, ideas and solutions across all levels of the system.

- Rapid adjustment to the shifting conditions and responses needed.

- Innovative approaches to meeting the needs of patient, families, HCW's and the system.

'This Department created space for debriefing, connection, and giving people permission to be vulnerable (led by leaders) and open. What may have been seen as "soft" or a "time waste" within a crisis situation, I think has been part of what has given us strength. Committed, supportive leadership, empowering others to spread greater dispersed leadership has been evident. The FG and Colab focused on emotional well-being and ways in which teams came together to share, to empathetically listen, communicating across functional lines, in multi-disciplinary teams, supporting each other. This resulted in a resilience and perseverance, not denying the fact that there is a lot of current trauma and exhaustion'. Quote from cofacilitator.

\section{2 | Learning about learning}

We have also learnt how to learn, and have found that engagement and learning is a positive and energising antidote in a pressurised environment. It requires a learning space that is considered safe, has intentional design and data support, and managers and clinicians with sufficient leadership authority and autonomy. It then enables the 
surfacing of emergent ideas, reflective dialogue and creative problem solving. The power to put ideas to test and show improvement gives hope and encourages further improvements.

\subsection{Connectedness and collaborative practice}

Connectedness and collaborative practices have, finally, been important in enabling such learning spaces. They support partnerships that have diverse strengths, as needed in complex systems and collaborative learning strengthens the strategic intent of being a transformational learning organisation.

System readiness in the WC was enhanced, for example, through embedded researchers and a universityfacilitated journal club. ${ }^{11}$ The IHI partnership shared international learnings and created a website for the initiative: https://community.ihi.org/za/gi/tools. The leadership coaching partner supported system-wide healing and grieving approaches. Labour organisations were invaluable in the interface between the shop floor and the management. Regular, open and transparent engagement with executive management built their trust in the efforts to prepare and protect staff. This assisted greatly in dealing with staff anxiety and fear.

At the frontline, virtual and live huddles embodied the need for human connectedness and the flow of information. WhatsApp groups were the most widely utilised, whilst daily huddles (in-person or virtual) amongst clinicians, managers or staff in a healthcare setting, connected a system of interrelationships. Allowing frontline decision-making and the forming of teams across silos also took the pressure away from the top and empowered the frontline. It also countered decision-making fatigue across the system.

\section{4 | CONCLUSIONS AND POLICY RECOMMENDATIONS}

Overall, then, we have found that a tiered system of rapid learning energises a stressed system; that authorising the testing of ideas (even failed attempts) empowers; and that connecting pockets of learning contributes to nurturing a learning organisation.

The \#StaffCare Colab Initiative has attracted both national and international attention. National health leaders have endorsed scaling the approach in South Africa, and three additional provinces have since joined the journey. The virtual rapid learning improvement approach was presented at a global IHI conference in November 2020.

However, the challenge of making the ideas, and what has worked in specific contexts, scalable and actionable across the system is considerable. The role of early adopters is to show that leading change in the face of extreme pressure is possible. This has not yet necessarily reached the whole system or the front-line in all spaces of the province. Diffusion strategies need to note and accommodate differences in contexts.

We propose that three transformational actions could deliver health systems that protect staff during good times and in times of system shocks, such as the COVID pandemic:

a. Continuously invest in building the foundations of system resilience in good times, to draw on in an acute crisis situation.

b. Leadership can deliver an explicit commitment to supporting health workers through decisive action across the system. It can establish a clearly stated goal at the highest levels of leadership to strengthen trust between the workforce and leadership, counter increased levels of fear in difficult times and offset conditions of chronic understaffing and overwork.

c. Optimise available resources and partners, act on improvement ideas and obstacles. Build trusting relationships amongst and across actors. 


\section{ACKNOWLEDGEMENTS}

The listed authors actively and equally participated in the writing of this article. However, the work of the \#StaffCare Colab Initiative is driven by a much larger group of people. The authors want to acknowledge everyone's contribution to the process and learning reflected in this article, and specifically the members of the Focus Group.

\section{CONFLICT OF INTERESTS}

The authors declare that there are no conflict of interests.

\section{ETHICS STATEMENT}

This article did not make use of original research, but reflects solely the authors' views and experiences.

\section{DATA AVAILABILITY STATEMENT}

The article is not based on research data, but authors' experiences and perspectives.

\section{ORCID}

Lucy Gilson (D) https://orcid.org/0000-0002-2775-7703

Uta Lehmann (D) https://orcid.org/0000-0002-2627-8954

\section{REFERENCES}

1. Fokazi S, Western Cape's decisive leadership "helped SA weather Covid-19 crisis". Times Live. September 16, 2020.

2. Gilson L, Barasa E, Brady L, et al. Collective sensemaking for action: researchers and decision makers working collaboratively to strengthen health systems. BMJ. 2021;372:m4650. https://doi.org/10.1136/bmj.m4650

3. Gilson L, Barasa E, Nxumalo N, et al. Everyday resilience in district health systems: emerging insights from the front lines in Kenya and South Africa. BMJ Glob Health. 2017;2(2):e000224. https://doi.org/10.1136/bmjgh-2016000224

4. Gilson L, Ellokor S, Lehmann U, Brady L. Organizational change and everyday health system resilience: lessons from Cape Town, South Africa. Soc Sci Med. 2020;266:113407.

5. Schneider H, Zulu JM, Mathias K, Cloete K, Hurtig A-K. The governance of local health systems in the era of sustainable development goals: reflections on collaborative action to address complex health needs in four country contexts. BMJ Glob Health. 2019;4(3):e001645. https://doi.org/10.1136/bmjgh-2019-001645

6. Gilson L, Pienaar D, Brady L, et al. Development of the health system in the Western Cape: experiences since 1994. In: Padarath A, Barron P, eds. South African Health Review. Durban: Health Systems Trust; 2017:59-69.

7. Institute for Healthcare Improvement. The Breakthrough Series: IHI's Collaborative Model for Achieving Breakthrough Improvement; 2003. www.IHI.org

8. Shanafelt T, Ripp J, Trockel M. Understanding and addressing sources of anxiety among health care professionals during the COVID-19 pandemic. JAMA. 2020;323:2133-2020. https://doi.org/10.1001/jama.2020.5893

9. Parbhoo AN, Numanoglu A, Argent AC, Franken M, Mukosi M, McCulloch MI. COVID-19: experience of a tertiary children's hospital in Western Cape province, South Africa. S Afr Med J. 2021:1-4.

10. Institute for Healthcare Improvement. 5 Tips for Better Huddles; 2018. http://www.ihi.org/communities/blogs/fivetips-for-better-huddles

11. The Western Cape HPSR Journal Club Team. "Not Just a Journal Club-It's where the Magic Happens": knowledge mobilization through co-production for health system development in the Western Cape province, South Africa. [published online ahead of print, August 1, 2020]. Int J Health Policy Manag. https://doi.org/10.34172/ijhpm.2020.128

How to cite this article: Engelbrecht B, Gilson L, Barker P, et al. Prioritizing people and rapid learning in times of crisis: A virtual learning initiative to support health workers during the COVID-19 pandemic. Int J Health Plann Mgmt. 2021;36(S1):168-173. https://doi.org/10.1002/hpm.3149 